\title{
Using CPT to Estimate an Aquifers Heterogeneity
}

\author{
Axel Tillmann, Forschungszentrum Jülich GmbH, Jülich, Germany \\ Zsuzsanna Nyari, Eötvös Loránd Geophysical Institute, Budapest, Hungary \\ Andreas Englert, Forschungszentrum Jülich GmbH, Jülich, Germany \\ Imre Fejes, Eötvös Loránd Geophysical Institute, Budapest, Hungary \\ Jan Vanderborght, Forschungszentrum Jülich GmbH, Jülich, Germany \\ Harry Vereecken, Forschungszentrum Jülich GmbH, Jülich, Germany
}

\begin{abstract}
The intensive growth of industrial and agricultural activity causes an increase of polluted areas. In order to predict the spreading of near-surface contamination it is essential to be familiar with the hydrogeological parameters of the investigated earth. The cone penetration technology is capable to resolve the structure of the subsurface in detail and logs various physical parameters during soil penetration. Cone penetration tests (CPT) were performed at the test site Krauthausen to investigate the aquifer's heterogeneity in detail.

We present the results of the CPT survey at the test site and the estimated three dimensional heterogeneous distribution of physical soil properties. We estimated the hydraulic conductivity from those data using regression analysis. Therefore the CPT method is capable to gain a spatial, highly resolved data set of the hydraulic conductivity distribution. Furthermore we used this data set to estimate the spatial heterogeneity of hydraulic conductivity, i.e. the correlation length and anisotropy within the aquifer.
\end{abstract}

\section{Introduction}

The Krauthausen test site is situated approximately $10 \mathrm{~km}$ northwest of the city of Düren and $8 \mathrm{~km}$ from Jülich, Germany, and has an extension of 200x70 m. The field site is located in the southern part of the Lower Rhine Embayment, where quaternarian sediments are mostly fluvial deposits from the river system of Rhine and Maas covered by aeolian sediments. Sequences of permeable and impermeable layers lead to a typical multi-layer aquifer system. Due to northwestsoutheast striking faults, the Lower Rhine Embayment is divided into several tectonic compartments. The Krauthausen test site is located on a small inserted block between the Rur block and the Erft block.

The test site was set up in 1993 by the Forschungszentrum Jülich (details are given in Döring, 1997; Vereecken et al., 1999; Vereecken et al., 2000; Englert, 2003) to perform experiments on water flow and solute transport processes. Up to now studies at Krauthausen test site focus on the uppermost aquifer in a depth from from 2 to $11 \mathrm{~m}$ covered by loess sediments. The aquifer material consists mainly of gravelly and sandy sediments deposited by the braided river system of the Rur. The clay and silt content of the aquifer sediments vary between $0.5 \%$ and $7.5 \%$, and the mean total porosity is $26 \pm 7 \%$. The local base of the aquifer in a depth of 11 to $13 \mathrm{~m}$ consists of intermitting thin layers of clay and silt. 
In order to ensure sufficient monitoring of the spatial and temporal distribution of the tracer substances as well as to characterize the heterogeneity of the aquifer, 75 observation wells with a diameter of $50 \mathrm{~mm}$ were installed (for details see Vereecken et al., 1999). In the scope of the installation of the observation wells, drillings of $324 \mathrm{~mm}$ diameter were deepened using a dry rotary drilling method. Three drillings (number B07, B22, and B32 located according to Figure 1 were sampled completely, the other drillings were sampled only at several depths or not sampled at all. The grain size distribution was determined from the soil samples by sieving in depth intervals of either $10 \mathrm{~cm}$ at B07 and B22 and 20cm at B32. The grain size analysis was used to determine local hydraulic conductivities, e.g. with the method of Bialas and Kleczkowski, 1970.

Apart from the above mentioned method pumping test data showed a mean hydraulic conductivity of $3.8 \cdot 10^{-3} \mathrm{~m} / \mathrm{s}$ (Vereecken et al., 2000).

\section{Cone Penetration Tests}

Cone penetration tests (CPT) were performed at the test site Krauthausen to investigate the aquifer's structural heterogeneity (see also Tillmann et al., 2004). At locations in a central area of 30x20 m of the test site shown in Figure 1 we performed 77 cone penetration tests down to $16 \mathrm{~m}$ depth. High resolution measurements (with a vertical spacing of $10 \mathrm{~cm}$ ) of cone pressure were carried out during the pushing process with a sensor placed on the tip of the rod. After the pushing process a passive natural gamma probe and two radioactive probes (i.e. a gamma-gamma and a neutron $\log$ ) were moved inside the hollow rods. The measured natural gamma activity is related to the clay content of the soil. The gamma-gamma and neutron probes provide information about the bulk density and the water content respectively from the radiation scattering characteristics of the soil. Therefore these probe are calibrated against reference materials. A more detailed introduction into the CPT method can be found e.g. in Fejes \& Jósa, 1990.

\section{Hydraulic conductivity estimation}

We postulate a relationship between a number of physical parameters measured during cone penetration tests and the hydraulic conductivity estimation via the grain size distribution. The determination and validation of the postulated relationship is shown in the following. The grain size distribution is a reliable quantitative describtion of sediments, and it is easy to obtain it from drilling samples. A simple relationship to derive the hydraulic conductivity from the grain size distribution is published in Bialas and Kleczkowski, 1970, where following relation is found:

$$
K_{h}=0.0036 \cdot d_{20}{ }^{2.3}
$$

where the hydraulic conductivity, $K_{h}$, is a function of the diameter $d_{20}$ only. The $20^{t h}$ percentile $d_{20}$ represents the diameter, where the cumulative grain size distribution has the value 0.20 . To perform a prediction of hydraulic conductivity using the Bialas approach, the diameter $d_{20}$ has to be estimated from cone penetration test data. Since there is no analytical function between the measured CPT data and the grain diameter $d_{20}$, we have to find an empirical one. This is done by correlating $d_{20}$ derived from drilling samples and data sets from CPT performed very close to those drillings. 


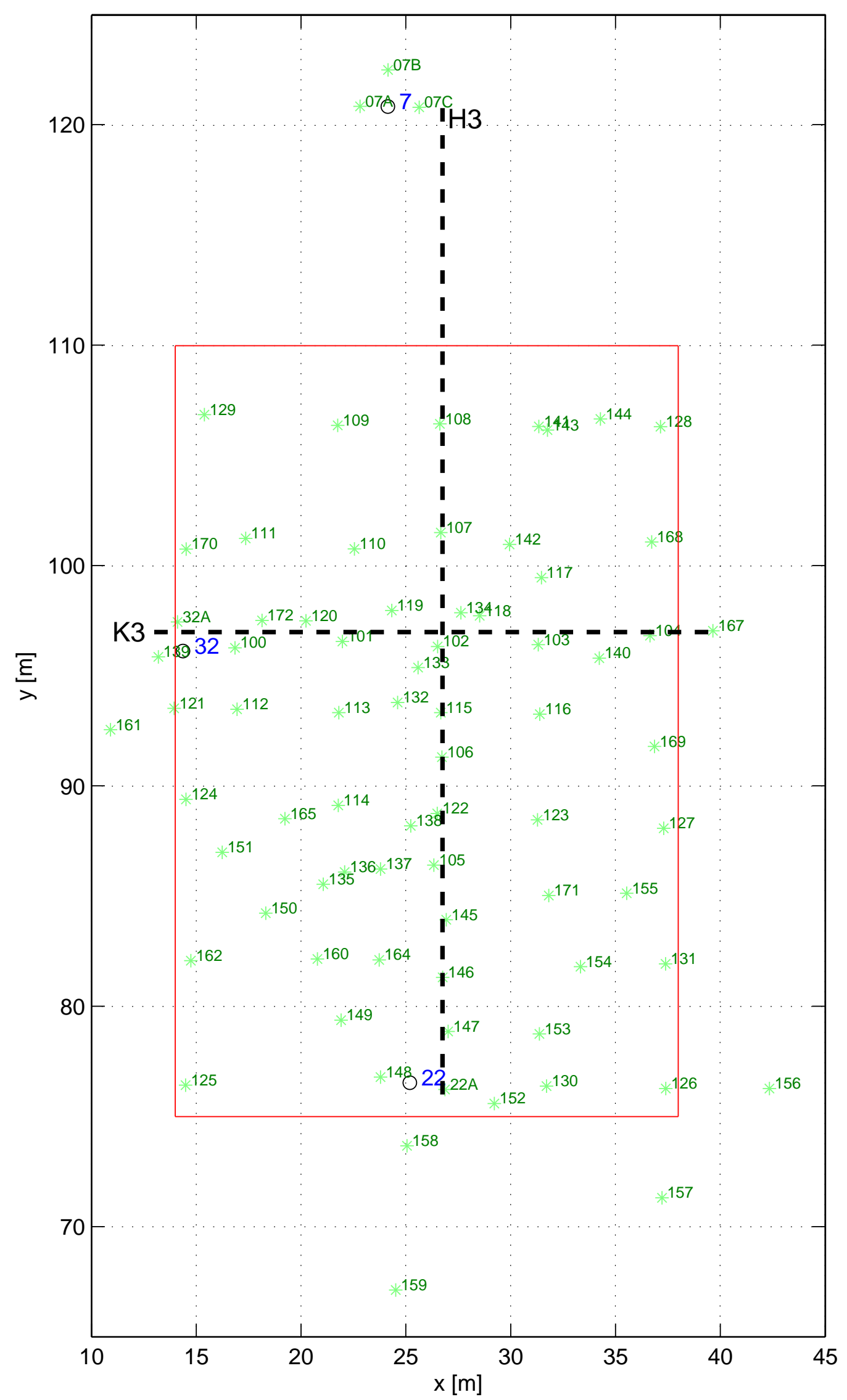

Figure 1: Location of the boreholes (blue circles) and cone penetration tests (green asterisks) at the central area of the Krauthausen test site. $\mathrm{H} 3$ and $\mathrm{K} 3$ denote the profiles shown in detail in Fig. 3. 
Since the diameter $d_{20}$ is varying in order of magnitudes we will use the decadic logarithm $\log _{10} d_{20}$ and assume $\log _{10} d_{20}$ to be a linear function of the measured data set $\underline{m}$ retrieved during cone penetration tests. We can express the linear function by the following equation:

$$
\log _{10} d_{p, 20, n}=\underline{\mathbf{m}}_{n}^{T} \underline{\mathbf{p}}
$$

where $d_{p, 20, n}$ is the predicted diameter and $\underline{\mathbf{m}}_{n}$ is the column vector containing the measured data set from CPT at the position $n$ respectively. $\underline{p}$ is a column vector containing the linear factors, which are valid for all measurement points $n \in\{1 . . N\}$, if the assumption of a linear functionality is valid. For all data sets measured at all $N$ locations Eq. (2) is extended to a linear equation system. Written in matrix notation we get:

$$
\log _{10} \underline{\mathrm{d}}_{p, 20}=\underline{\underline{\mathrm{M}}} \underline{\underline{\mathrm{p}}} .
$$

To find the appropriate vector of linear factors $\underline{p}$, the linear equation system must be solved. Since there are more measurement locations than elements of vector $\mathrm{p}$ the linear equation system is overdetermined. A gaussian approach is used to solve Eq. (3) in a least squares sense:

$$
\underline{p}=\left(\underline{\underline{M}}^{T} \underline{\underline{M}}\right)^{-1} \underline{\underline{M}}^{T} \underline{\mathrm{d}} .
$$

Once vector $\underline{\mathrm{p}}$ is determined from the comparsion of core and CPT data, it can be used to directly transform further CPT measurements into estimated values of the hydraulic conductivity $K_{h}$ at a new location using the Bialas relationship from Eq. (1) and Eq. (2)

$$
K_{h}=0.0036 \cdot 10^{2.3\left(\underline{\mathrm{m}}_{n}{ }^{T} \underline{\mathrm{p}}\right)} .
$$

As one can see in Figure 1 the screened drillings 07, 22, and 32 are surrounded by minimum two CPT locations as close as 1 to $1.5 \mathrm{~m}$. To find the appropriate linear coefficients in Eq. 3, we use these CPT locations as calibration data set against the results from traditional grain size analysis from cores published in Döring, 1997. For the first run we used all information available from CPT, i.e. mechanical cone resistance $c_{r}$, natural gamma activity $\gamma$, bulk density $\varrho_{b}$, water content $\theta$ and electrical resistivity $\rho$. To estimate the information content of the single measured data sets, we build the correlation coefficient matrix for $\log _{10} d_{20}$ and the data sets in $\underline{\underline{M}}$. The resulting matrix is shown in Table 1.

\begin{tabular}{|r|rrrrr|}
\hline & $\log _{10} d_{20}$ & $c_{r}$ & $\gamma$ & $\varrho_{b}$ & $\theta$ \\
\hline $\log _{10} d_{20}$ & 1.00 & $\mathbf{0 . 6 5}$ & $\mathbf{- 0 . 5 6}$ & $\mathbf{0 . 7 0}$ & 0.16 \\
$c_{r}$ & $\mathbf{0 . 6 5}$ & 1.00 & -0.59 & 0.72 & 0.00 \\
$\gamma$ & $\mathbf{- 0 . 5 6}$ & -0.59 & 1.00 & -0.70 & -0.69 \\
$\varrho_{b}$ & $\mathbf{0 . 7 0}$ & 0.72 & -0.70 & 1.00 & 0.32 \\
$\theta$ & 0.16 & 0.00 & -0.69 & 0.32 & 1.00 \\
\hline
\end{tabular}

Table 1: Correlation coefficients between $\log _{10} d_{20}$ and the CPT data. The highest absolute value in the first row determining the best correlating parameters are printed bold face. 
From Table 1 we derive the correlation coefficients with the highest absolute value in the first row, i.e. the best correlations between $\log _{10} d_{20}$ and the single data sets. Therefore we indentified the mechanical cone resistance $c_{r}$, the natural gamma activity $\gamma$, and the bulk density $\varrho_{b}$ as promising candidates for gaining an empirical relationship.

With that knowledge the general Equation (3) can be formulated for this specific problem to:

$$
\log _{10}\left(\begin{array}{c}
d_{201} \\
d_{202} \\
d_{203} \\
\ldots \\
d_{20 N}
\end{array}\right)=\left(\begin{array}{cccc}
c_{r 1} & \gamma & \varrho_{b 1} & 1 \\
c_{r 2} & \gamma & \varrho_{b 2} & 1 \\
c_{r 3} & \gamma & \varrho_{b 3} & 1 \\
\cdots & \cdot & \ldots & \ldots \\
c_{r N} & \gamma & \varrho_{b N} & 1
\end{array}\right)\left(\begin{array}{c}
p_{1} \\
p_{2} \\
p_{3} \\
p_{4}
\end{array}\right)
$$

The linear coefficients $p_{1}, p_{2}, p_{3}, p_{4}$, which are the unknowns in Eq. (6), are computed using Eq. (4).

In this specific case 320 data points are available where all necessary information is present. Therefore the linear coefficients could be estimated upon a good database. With the knowledge of $\underline{\mathrm{p}}$ Eq. (2) could be formulated as

$$
\log _{10} d_{p, 20}=1.06 \cdot 10^{-2} c_{r}-8.38 \cdot 10^{-5} \gamma+1.57 \varrho_{b}-6.86
$$

This equation is the key to predict the diameter $d_{20}$ from CPT measurements for further use in equation Eq. (1). To estimate the error of the prediction, we correlate the predicted diameter $d_{p, 20}$ with the diameter $d_{20}$ gained from the cumulative grain size distribution. The predicted and measured logarithmic diameters correlate with a correlation coefficient of 0.737 and a standard deviation of 0.303 , i.e. the diameter can be predicted with an accuracy of factor 2 .

Once the diameter $d_{20}$ is derived using Eq. (7) from the field data, Eq. (1) can be used to estimate the hydraulic conductivity at the CPT locations. Or, inserting Eq (7) into Eq. (1) and perform some transformations, we obtain:

$$
K_{h}=10^{2.438 \cdot 10^{-2}} c_{r}-1.927 \cdot 10^{-4} \gamma+3.611 \varrho_{b}-18.222 .
$$

\section{Hydraulic conductivity distribution}

Figure 2 shows the predicted hydraulic conductivities at the drilling locations B 07, B 22, and B 32 (plotted black) versus the estimated values from CPT measurements (plotted red). The confidence interval of the estimated values plotted as red lined area in Fig. 2 was computed with regard to the standard deviation for $\log _{10} d_{p, 20}$ of 0.303 . If we compare both results, we can state that the hydraulic conductivity is estimated fairly well. There are only a very few locations, where the estimation deviate within one order of magnitude or more. These are located mainly in the unsaturated zone above the groundwater level marked as blue line in the Fig. 2. 


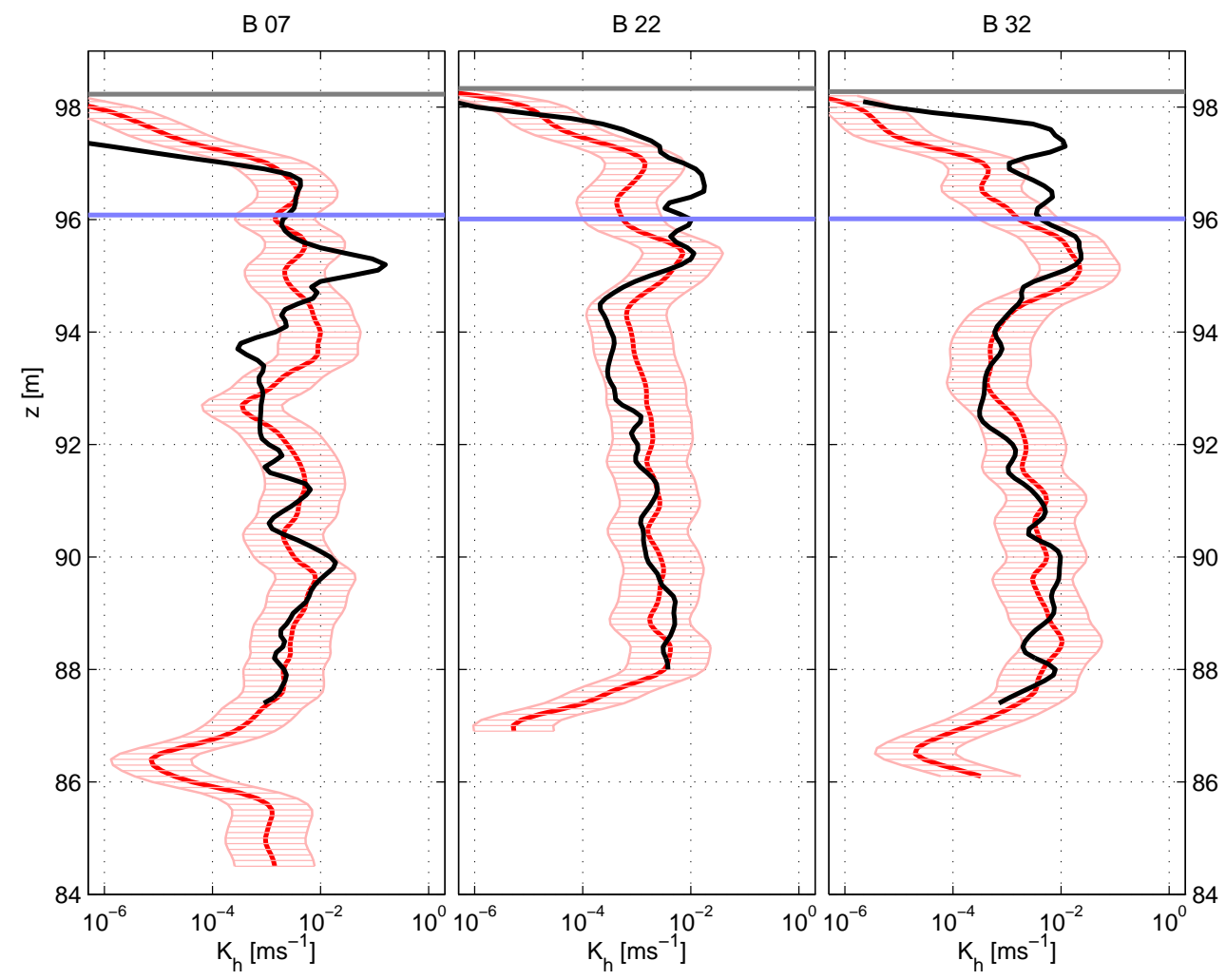

Figure 2: Comparison of predicted hydraulic conductivity from core analysis (black) vs. CPT (red).

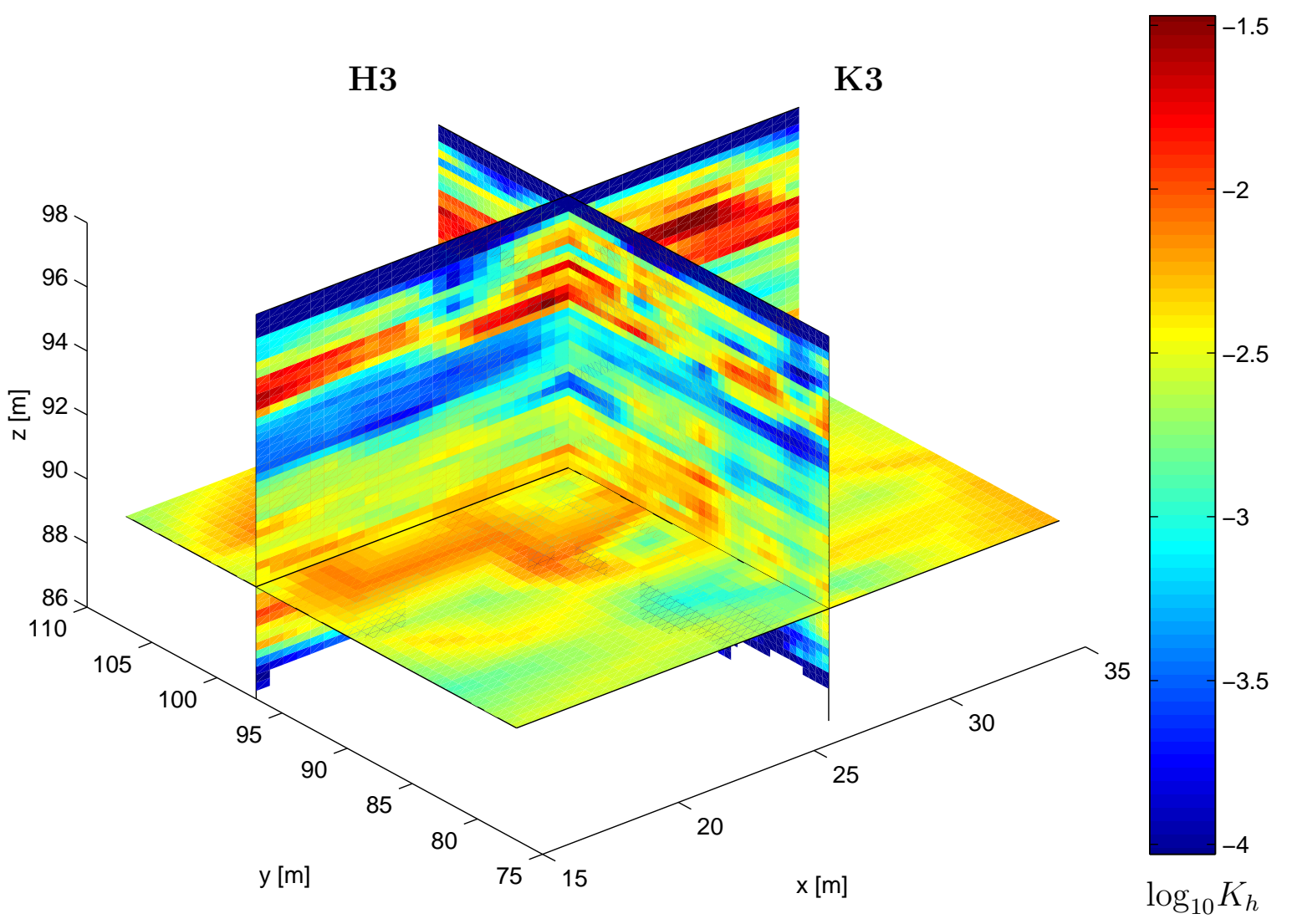

Figure 3: Predicted logarithm of the hydraulic conductivity distribution from CPT. 
Values for $\log _{10} K_{h}$ are interpolated linearly using the algorithm of Barber et al., 1996 to produce the three-dimensional $K_{h}$ distribution for the test site. Figure 3 shows three specific cuts , i.e. the vertical cuts along the profiles H3 and K3 marked in Fig. 1 and the cut along the height level of $90 \mathrm{~m}$. From the vertical cuts we can recognize the layered structure of the test sites aquifer. The low hydraulic conductivities $\left(10^{-4} \mathrm{~m} / \mathrm{s}\right.$ and below) of the top loess layer at $\approx 97.5 \mathrm{~m}$ and the clay/silt aquifer basis at $\approx 87 \mathrm{~m}$ are clearly visible. Also the higher hydraulic conductivities of $10^{-2} \mathrm{~m} / \mathrm{s}$ and higher at height levels from 94 to $96 \mathrm{~m}$ due to higher gravel content are in evidence. The layers lateral inhomogeneity is also noticable, especially from the horizontal cut. There the lateral extension of a high conductivity region is shown.

\section{Heterogeneity of hydraulic conductivity}

In accordance with standard practice (see e.g. Deutsch and Journel, 1992), the variogram of the logarithmic hydraulic conductivity $\log _{10} K_{h}(\underline{\mathrm{x}})$ is used for the evaluation of the experimental data sets. The variogram analysis delivers the spatial correlation lengths between the data points within the examined region. The estimated variogram $V(|d \underline{x}|)$ from the experimental data set is used:

$$
V(|d \underline{\mathbf{x}}|)=\frac{1}{2 N} \sum_{i=1}^{N}\left(z\left(\underline{\mathbf{x}}_{i}\right)-z\left(\underline{\mathbf{x}}_{i}+d \underline{\mathbf{x}}\right)\right)^{2},
$$

where $\underline{x}$ are the coordinates of an observation and $d \underline{x}$ is the distance vector to a second observation. The estimated variogram $V(|d \underline{\mathbf{x}}|)$ is fitted within the method of least squares using the gaussian model with

$$
V(|d \underline{\mathbf{x}}|)=C_{0} \cdot\left(1-e^{-|\underline{\mathrm{dx}}|^{2} / \lambda^{2}}\right)
$$

In the above equation $C_{0}$ is the sill and $\lambda$ the correlation length.

To determine the spatial correlation of the hydraulic conductivity, i.e. the correlation lengths, variogram analyses were performed on the estimated hydraulic conductivities according to Eq. (9). Therefore we calculated pairwise the distance vectors between all CPT locations. These difference vectors were sorted after length and direction, with a length interval of $1 \mathrm{~m}$ and a angle interval of 10 degrees. The computation of the variograms were performed for each segment with a depth interval of $\pm 1 \mathrm{~m}$ using Eq. (9). The resulting estimated variograms were fitted in a least squares sense with Eq. (10), i.e. the gaussian model. From that fits the lateral correlation lengths were derived for a specific depth interval and plotted against the azimuth angle (see Fig. 4). As the figure shows, there is a strong azimuthal anisotropy in the estimated lateral correlation length. Depending on the height level the maximum correlation length varies from 10 to $20 \mathrm{~m}$. The direction of longer correlation length remains stable approx. in north-south direction with exception of the intermediate height, where the direction tends towards north-east direction. 

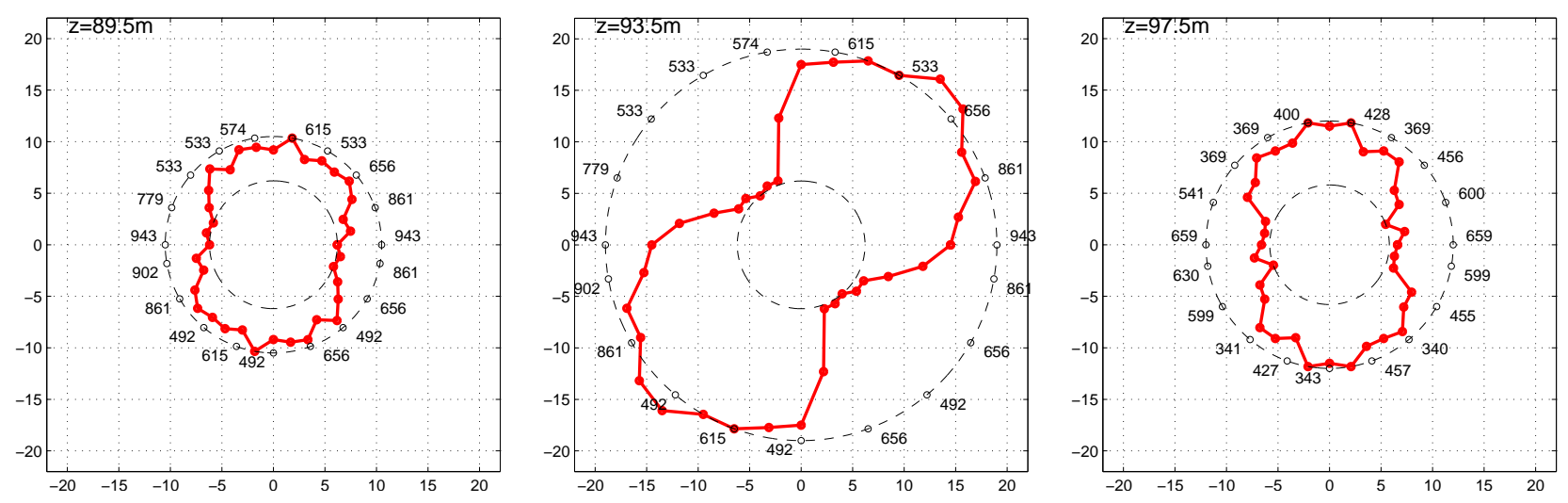

Figure 4: Correlation length of hydraulic conductivity with azimuth at different height levels for the gaussian model. The height levels represent locations in the lower aquifer, upper aquifer, and the soil respectively.

\section{Summary and Conclusion}

We performed $77 \mathrm{CPT}$ at test site Krauthausen with high resolution in horizontal and vertical direction. This survey provided a data set of approximately 10000 single measurements of physical parameters, e. g. cone pressure, natural gamma activity, bulk density and water pore volume. We linked prior measurements of grain size distribution at approx. 300 single locations to the physical parameters from CPT using regression analysis. This enabled us to predict the $20^{\text {th }}$ percentile of the grain size distribution within an accuracy of factor 2. Thereafter we formulated an empirical relationship to predict the hydraulic conductivity from the $20^{t h}$ percentile for the entire test site. A layer-wise geostatistical analysis of these hydraulic conductivities showed strong variations in correlation length and horizontal anisotropy. Further work will show the effects of these findings on flow and transport processes.

\section{Acknowledgements}

We wish to thank the team of János Stickel from ELGOSCAR 2000, Budapest, Hungary, for performing the cone penetration tests. This work is funded partly by the NATO Collaborative Linkage Grant No. EST 979868.

\section{References}

1. Barber, C. B., D.P. Dobkin, and H.T. Huhdanpaa, 1996. The Quickhull Algorithm for Convex Hulls. ACM Transactions on Mathematical Software, 22,4, 469-483

2. Bialas, Z., and A. S. Kleczkowski, 1970. Über den praktischen Gebrauch von einigen empirischen Formeln zur Berechnung des Durchlässigkeitskoeffzienten K. Archivum Hydrotechniki, Warschau, 
3. Deutsch, C.V. and A.G. Journel, 1992. GSLIB: Geostatistical Software Library and User's Guide. Oxford University Press, Oxford,

4. Döring U., 1997. Transport der reaktiven Stoffe Eosin, Uranin und Lithium in einem heterogenen Grundwasserleiter. PhD thesis, Christian-Albrechts Universitat Kiel, Kiel, Germany,

5. Englert A., 2003. Measurement, Estimation and Modelling of Groundwater Flow Velocity at Krauthausen Test Site. PhD thesis, RWTH Aachen, Aachen, Germany,

6. Fejes I. and Jósa E., 1990. The Engineering Geophysical Sounding Method: Principles, Instrumentation, and Computerised Interpretation. In: Geotechnical and Environmental Geophysics, Volume II: Environmental and Groundwater, SEG, Tulsa, Oklahoma, 321-331

7. Tillmann, A., Nyari, Z., Fejes, I., Vanderborght, J., and Vereecken, H., 2004. Cone Penetration Tests for investigation of heterogeneity in an aquifer at Krauthausen. EAGE 66th Conference and Exhibition, Extended Abstracts, Paris, P-157

8. Vereecken, H., Döring, U., Hardelauf, H., Jaekel, U., Neuendorf, O., Schwarze, H. and Seidemann, R., 1999. Analysis of solute transport in a heterogeneous aquifer: the Krauthausen field experiment. 1. Experimental set-up, sediment characterization and moment analyses. Forschungszentrum Jülich GmbH, Internal report Nr. 500798,

9. Vereecken, H., Döring, U., Hardelauf, H., Jaekel, U., Hashagen, U., Neuendorf, O., Schwarze, H. and Seidemann, R., 2000. Analysis of solute transport in a heterogeneous aquifer: the Krauthausen field experiment. Journal of Contaminant Hydrology, 45, 329-358 